\title{
Supramolecular organizing centers (SMOCs) as signaling machines in innate immune activation
}

\author{
QIAO Qi ${ }^{1,2} \&$ WU Hao ${ }^{1,2 *}$ \\ ${ }^{1}$ Department of Biological Chemistry and Molecular Pharmacology, Harvard Medical School, Boston, MA 02115, USA; \\ ${ }^{2}$ Program in Cellular and Molecular Medicine, Boston Children's Hospital, Boston, MA 02115, USA
}

Received September 16, 2015; accepted October 16, 2015; published online October 27, 2015

\begin{abstract}
Innate immunity offers the first line of defense against infections and other types of danger such as tumorigenesis. Its discovery provides tremendous therapeutic opportunities for numerous human diseases. Delving into the structural basis of signal transduction by innate immune receptors, our lab has recently helped to establish the new paradigm in which innate immune receptors transduce ligand-binding signals through formation of higher-order assemblies containing intracellular adapters, signaling enzymes and their substrates. These large signalosome assemblies may be visible under light microscopy as punctate structures in the $\mu \mathrm{m}$ scale, connecting to the underlying molecular structures in the $\mathrm{nm}$ scale. They drive proximity-induced enzyme activation, and provide a mechanism for signaling amplification by nucleated polymerization. These supramolecular signaling complexes also open new questions on their cellular organization and mode of regulation, pose challenges to our methodology, and afford valuable implications in drug discovery against these medically important pathways.
\end{abstract}

innate immunity, caspase-recruitment domain, pyrin domain, supramolecular organizing centers, filament

Citation: Qiao Q, Wu H. Supramolecular organizing centers (SMOCs) as signaling machines in innate immune activation. Sci China Life Sci, 2015, 58: 1067-1072, doi: 10.1007/s11427-015-4951-z

\section{The innate immune system}

The effects of innate immune activation have been likely known for as long as humans emerged, and documented for thousands of years as fever, heat, redness, swelling and pain. The use of infection to induce immune protection against tumors has been widely experimented with for cancer therapy since more than 100 years ago, one example being in the treatment of malignant tumors by repeated bacterial inoculations to induce acute erysipelas [1]. However, it was not until recently when receptors that directly recognize conserved features of pathogens were identified that our understanding on innate immunity started to grow exponentially [2-4], representing a revolution in immunology.

*Corresponding author (email: wu@ crystal.harvard.edu)
We now know that innate immunity is an equally important component of host defense as adaptive immunity. Because innate immunity uses germline-encoded receptors [2,5], it is immediate and acts before adaptive immunity has a chance to generate clonal selection mediated specific protection. Innate immunity also operates as the co-stimulator for adaptive immunity, and accounts for the indispensable role of adjuvants as the immunologist's "dirty little secret" in vaccination $[2,6,7]$. While adaptive immunity is limited to vertebrates, innate immunity is evolutionarily conserved and has been perfected over millions of years [8].

The innate immune system may be considered to comprise pattern recognition receptors (PRRs) that directly react to incoming danger signals and cytokine receptors that amplify the initial responses [9]. A number of families of PRRs have been characterized (Figure 1). While the Toll-like receptor (TLR) family detects extrinsic pathogenic signals 


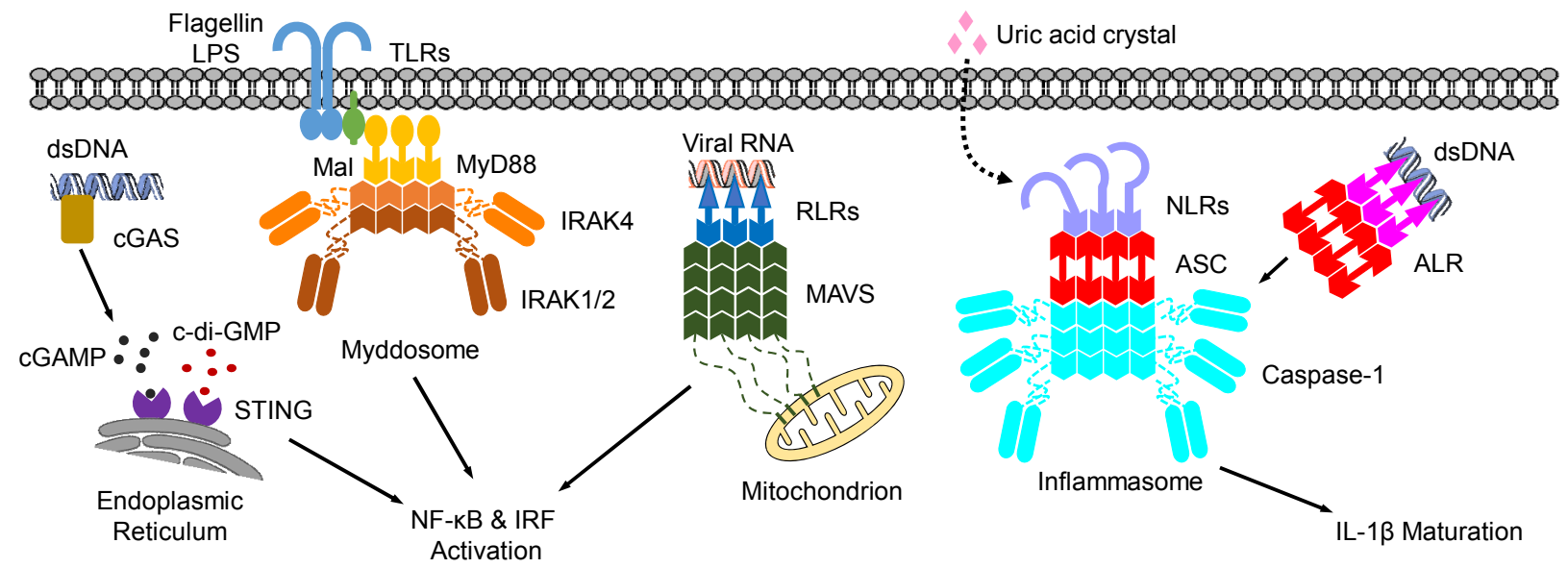

Figure 1 Overview of innate immune signaling pathways. The Toll-like receptor (TLR) family detects conserved pathogen-associated molecules such as flagellin and lipopolysaccharide (LPS) in the extracellular environment and recruits intracellular signaling adapters myeloid differentiation primary response gene 88 (MyD88) and MyD88 adapter-like (Mal) through TIR domain interactions. Binding of interleukin-1 receptor associated kinases (IRAKs) to MyD88 to assemble the Myddosome leads to activation of these kinases and induction of NF- $\mathrm{KB}$ and IRF transcriptional activities. RIG-I-like receptor (RLR) family senses intracellular viral RNAs. Through promoting mitochondrial antiviral-signaling protein (MAVS) filament formation, an RLR eventually activates IRF, leading to secretion of type I interferons. The cyclic GMP-AMP synthase (cGAS) recognizes cytosolic DNA and produces cyclic GMP-AMP (cGAMP) as a secondary messenger. cGAMP and bacterial c-di-GMP activate stimulator of interferon genes (STING) and result in IRF activation. The nucleotide-binding domain and leucine-rich domain containing receptors (NLR) and absent in melanoma 2 (AIM2)-like receptors (ALR) respond to large varieties of pathogenic signals in the cytosol and outside the cell. The adaptor apoptosis-associated speck-like protein containing a CARD (ASC) can be recruited through receptor

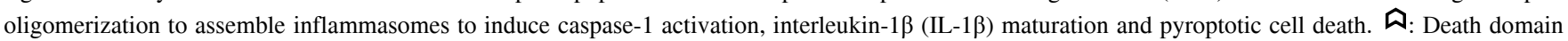
superfamily members.

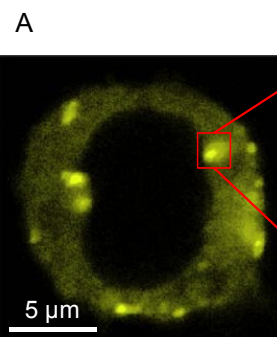

MALT1-YFP

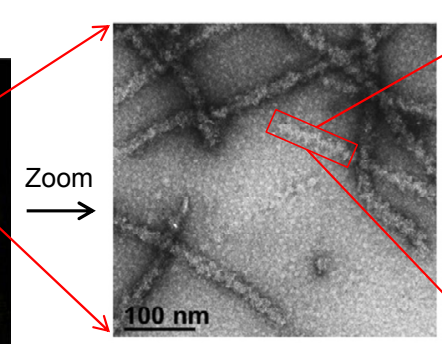

CARMA1/BCI10/MALT1 signalosome
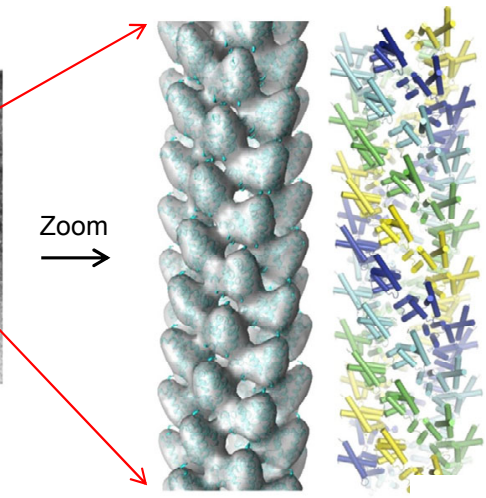

BCl10 CARD

filament

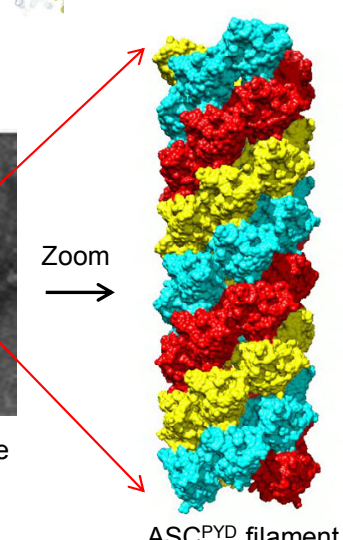

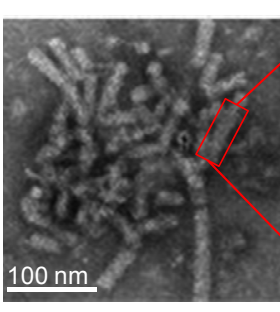

NLRP3 inflammasome

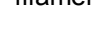

B

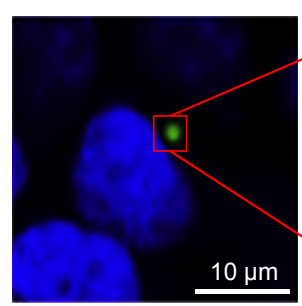

ASC-GFP
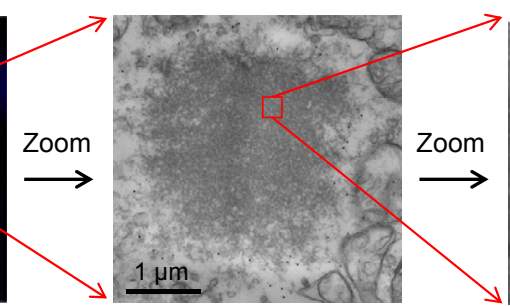

$1 \mu \mathrm{m}$
Figure 2 Zoom into the signaling puncta. A, Confocal microscopy shows upon stimulation, CARMA1, Bcl10 and MALT1 assemble into punctate structures in T-cells [47]. In vitro reconstituted CBM complex reveals a filamentous morphology under the electron microscope. Further structural studies identified the core part of the complex as the Bcl10 CARD filament in a helical symmetry [30]. B, Inflammasome puncta under the confocal microscope [48] and electron microscope [31]. In vitro reconstituted NLRP3 inflammasome was observed as bundles filaments. An ASC PYD helical filament structure was solved by cryo-EM at $3.8 \AA$ A resolution [31]. 
and intrinsic dangers on the cell surface and in the endosome $[10,11]$, the RIG-I-like receptor (RLR) family senses intracellular viral RNAs [12]. They both activate nuclear factor $\kappa \mathrm{B}(\mathrm{NF}-\kappa \mathrm{B})$ and interferon regulatory factor (IRF) transcription factors to induce cytokine production. The nucleotide-binding domain and leucine-rich domain containing receptors (NLR) $[13,14]$ and absent in melanoma 2 (AIM2)-like receptors (ALR) [15-17] respond to a wide variety of pathogenic and intrinsic dangers to form inflammasomes, inducing caspase-1 activation, interleukin-1 $\beta$ maturation and cell death $[18,19]$. Some NLRs also stimulate NF- $\kappa B$ and IRF activation [20]. The cyclic GMP-AMP synthase (cGAS) detects cytoplasmic double-stranded DNA to synthesize cyclic GMP-AMP (cGAMP), which in turn binds and activates stimulator of interferon genes (STING), leading to robust IRF activation [21]. Cytokines secreted upon PRR activation further activate cytokine receptors, such as those in the tumor necrosis factor receptor (TNFR), interleukin-1 receptor (IL-1R), and interferon receptor families [9]. Additionally, lymphocytes also induce innate-like, inflammatory responses, including $\mathrm{NF}-\kappa \mathrm{B}$ activation by T-cell receptors (TCR) and B-cell receptors (BCR) through the CARMA1/Bcl10/MALT1 (CBM) signaling complex $[22,23]$, further expanding the role of innate immunity in immune responses in general.

\section{Signaling platforms formed by helical assem- blies of death-fold domains and proximity-driven enzyme activation}

Our interest in innate immunity began with receptors in the TNFR and IL-1R families. Through biochemical and structural studies, our initial anticipation on a classical mode of signaling for these receptors was replaced by the new observation of higher order signaling complexes that execute signal transduction across the cell membrane and signal amplification inside the cell. A turning point in these studies was the realization that the family of death-fold domains, ubiquitously present in innate immune signaling pathways, assemble oligomeric complexes using helical symmetry [24]. Initially discovered from the cytoplasmic domain of TNF-R1 [25], the death-fold superfamily is composed of four domains, death domains (DD), caspase activation and recruitment domains (CARD), death-effector domains (DED) and pyrin domains (PYD) [26]. Structurally, all death-fold family members share a conserved six-helix bundle fold, but with distinct sequence and surface features for mediating specific self-association and recruitment [26].

Through crystal structure determination, supplemented with imaging by electron microscopy, our laboratory discovered that DDs form oligomeric complexes with unusual stoichiometries, such as the 5:7 binary complex in the PIDDosome for caspase-2 activation, the 5:5 binary complex in the death inducing signaling complex, and the $6: 4: 4$ ternary Myddosome complex in TLR and IL-1R signal transduction [24,27,28]. Although the exact symmetries used for these assemblies differ, they are all helical symmetries, rather than point symmetries, which organize the death domain subunits into orderly structures [26]. As predicted by the polymerization ability of helical symmetries, many death-fold domains have subsequently been found to form helical filaments, such as the PYD and CARD in inflammasome structures and RIG-I signaling [29-33], further illuminating the higher-order nature of these complexes. The DD, DED, PYD and CARD often reside in proteins with enzyme domains such as caspase and kinase domains. By bringing these domains into the higher-order assemblies, the death-fold domain family promotes proximity-driven dimerization and allosteric activation of these enzymes to execute the signal transduction [34].

\section{Signal amplification by nucleated polymeri- zation}

One important principle in the involvement of filaments in innate immune signaling is nucleated polymerization in which one signaling protein induces filament formation of another signaling protein [29-31,35]. In our study of the CARMA1/Bcl10/MALT1 complex, which acts downstream of TCR and BCR for induction of NF- $\kappa \mathrm{B}$ activation [30], we found that while Bcl10 can form filamentous structures on its own, CARMA1 promotes Bcl10 filament formation by increasing the rate and decreasing the concentration threshold of Bcl10 polymerization. The stimulation by CARMA1 enhances with an increased oligomerization state of CARMA1. The more aggregated CARMA1 is, the more potent it is in this activity, explaining over-activation of the pathway by highly aggregated oncogenic CARMA1 mutants [36]. Our additional structure-guided studies confirmed that CARMA1 nucleates Bcl10 filament formation by providing an oligomeric platform to recruit Bcl10 for helical assembly [30]. Similar principles operate in the formation of ALR and NLR inflammasomes and RLR signaling complexes, in which the same helical symmetry is shared between the nucleator (e.g. CARMA1) and the polymerizer (e.g. Bcl10) [31,32,37].

The universal mechanism of nucleated polymerization affords an elegant mechanism of signal transduction and amplification in innate immunity [34]. In a classical signaling pathway such as those mediated by G-protein coupled receptors [38], ligand binding from outside the cell induces conformational changes that lead to promotion of the exchange of GDP for GTP of the bound heterotrimeric G proteins. The GTP-bound $\alpha$ subunits of $\mathrm{G}$ proteins dissociate from the $\beta$ and $\gamma$ subunits, each effecting target proteins for production of second messengers such as cAMP and for regulation of channel activities, respectively. For innate immune receptors, activating stimuli induce conformational 
changes to cause receptor clustering. Oligomerized receptors act as templates to recruit downstream signaling proteins to propagate the activation signal. By leading to polymerization of these signaling proteins, one receptor activates many signaling proteins, resulting in amplification of the signaling cascade. Therefore, nucleated polymerization may contribute to the sensitivity and the threshold response in the signal transduction of many innate immune receptors [39].

\section{Supramolecular organizing centers (SMOCs) in cells}

While studies in vitro have revealed biophysical insights into innate immune signalling, it is essential to extend these understandings to cellular systems. One emerging concept is that innate immune receptors not only induce the formation of these large signalosomes, they appear to use specific cellular locations for their assembly. Therefore, we previously put forward the concept of SMOCs as location-specific higher-order signalling complexes in which increased local concentrations of signalling components promote the intrinsically weak allosteric interactions required for enzyme activation [40]. For example, the TLR signaling complex Myddosome is assembled at the cell surface and the endosome, because the sorting adaptor protein TIRAP with promiscuous affinity to acidic phosphoinositides and phosphatidylserine on these membranes orchestrates the recruitment of Myddosome components [41,42]. Even though the RLRs are cytosolic receptors, the downstream adapter MAVS is localized at mitochondria, peroxisomes and the mitochondria-associated membranes of the endoplasmic reticulum (MAM), enabling SMOC assembly at each of these organelles [43-45]. The CBM signalling complex appears to be associated with the p62 adapter and autophagosomes [46]. The implications of SMOCs are yet to be clearly resolved. However, borrowing from the slogan "location, location, location" from real estate, the specific localizations of the signalosomes may assist the access to certain proteins or factors that facilitate assembly, signal transduction and amplification, and the reach of a response threshold of the cellular responses.

\section{Therapeutic implications}

An emerging hypothesis is that nearly every human disease has an inflammatory component, including cancers, autoimmune conditions and metabolic syndromes. Structural and functional studies on innate immunity, which is at the center of inflammation, have provided a treasure trove for disease prevention and treatment. The discovery of the higher-order nature of innate immune signaling complexes and their specific locations offers new angles for potential therapeutic interventions, for example, through disruption of the scaffolding functions of signaling proteins in addition to their enzyme activities, and interference of their localizations.

The authors declare that they have no conflict of interest.

1 Coley WB. The treatment of malignant tumors by repeated inoculations of erysipelas: with a report of ten original cases. Am J Med Sci, 1893, 105: 487-511

2 Janeway CA Jr. Approaching the asymptote? Evolution and revolution in immunology. Cold Spring Harb Symp Quant Biol, 1989, 54 Pt 1: 1-13

3 Poltorak A, He X, Smirnova I, Liu MY, Huffel CV, Du X, Birdwell D, Alejos E, Silva M, Galanos C, Freudenberg M, RicciardiCastagnoli P, Layton B, Beutler B. Defective LPS signaling in $\mathrm{C} 3 \mathrm{H} / \mathrm{HeJ}$ and C57BL/10ScCr mice: mutations in Tlr4 gene. Science, 1998, 282: 2085-2088

4 Medzhitov R, Preston-Hurlburt P, Janeway CA Jr. A human homologue of the Drosophila Toll protein signals activation of adaptive immunity. Nature, 1997, 388: 394-397

5 Medzhitov R, Janeway C Jr. Innate immune recognition: mechanisms and pathways. Immunol Rev, 2000, 173: 89-97

6 Medzhitov R, Janeway CA Jr. Innate immune recognition and control of adaptive immune responses. Semin Immunol, 1998, 10: 351-353

7 Iwasaki A, Medzhitov R. Regulation of adaptive immunity by the innate immune system. Science, 2011, 327: 291-295

8 Medzhitov R, Janeway Jr CA. An ancient system of host defense. Curr Opin Immunol, 1998, 10: 12-15

9 Yin Q, Fu TM, Li J, Wu H. Structural biology of innate immunity. Ann Rev Immunol, 2015, 33: 393-416

10 Netea MG, Wijmenga C, O'Neill LA. Genetic variation in Toll-like receptors and disease susceptibility. Nat Immunol, 2012, 13: 535-542

11 Song DH, Lee JO. Sensing of microbial molecular patterns by Toll-like receptors. Immunol Rev, 2012, 250: 216-229

12 Rawling DC, Pyle AM. Parts, assembly and operation of the RIG-I family of motors. Curr Opin Struct Biol, 2014, 25: 25-33

13 Mason DR, Beck PL, Muruve DA. Nucleotide-binding oligomerization domain-like receptors and inflammasomes in the pathogenesis of non-microbial inflammation and diseases. J Innate Immun, 2012, 4: 16-30

14 Vance RE. The NAIP/NLRC4 inflammasomes. Curr Opin Immunol, 2015, 32: 84-89

15 Barber GN. Innate immune DNA sensing pathways: STING, AIMII and the regulation of interferon production and inflammatory responses. Curr Opin Immunol, 2011, 23: 10-20

16 Loo YM, Gale M Jr. Immune signaling by RIG-I-like receptors. Immunity, 2011, 34: 680-692

17 Roberts TL, Idris A, Dunn JA, Kelly GM, Burnton CM, Hodgson S, Hardy LL, Garceau V, Sweet MJ, Ross IL, Hume DA, Stacey KJ. HIN-200 proteins regulate caspase activation in response to foreign cytoplasmic DNA. Science, 2009, 323: 1057-1060

18 Henao-Mejia J, Elinav E, Strowig T, Flavell RA. Inflammasomes: far beyond inflammation. Nat Immunol, 2012, 13: 321-324

19 Rathinam VA, Vanaja SK, Fitzgerald KA. Regulation of inflammasome signaling. Nat Immunol, 2012, 13: 333-332

20 Ting JP, Duncan JA, Lei Y. How the noninflammasome NLRs function in the innate immune system. Science, 2010, 327: 286-290

21 Sun L, Wu J, Du F, Chen X, Chen ZJ. Cyclic GMP-AMP synthase is a cytosolic DNA sensor that activates the type I interferon pathway. Science, 2013, 339: 786-791

22 Thome M. CARMA1, BCL-10 and MALT1 in lymphocyte development and activation. Nat Rev Immunol, 2004, 4: 348-359

23 Blonska M, Lin X. CARMA1-mediated NF-kappaB and JNK activation in lymphocytes. Immunol Rev, 2009, 228: 199-211

24 Lin SC, Lo YC, Wu H. Helical assembly in the MyD88- 
IRAK4-IRAK2 complex in TLR/IL-1R signalling. Nature, 2010, 465: 885-890

25 Tartaglia LA, Ayres TM, Wong GH, Goeddel DV. A novel domain within the $55 \mathrm{kd}$ TNF receptor signals cell death. Cell, 1993, 74: 845-853

26 Ferrao R, Wu H. Helical assembly in the death domain (DD) superfamily. Curr Opin Struct Biol, 2012, 22: 241-247

27 Park HH, Logette E, Raunser S, Cuenin S, Walz T, Tschopp J, Wu H. Death domain assembly mechanism revealed by crystal structure of the oligomeric PIDDosome core complex. Cell, 2007, 128: 533-546

28 Wang L, Yang JK, Kabaleeswaran V, Rice AJ, Cruz AC, Park AY, Yin Q, Damko E, Jang SB, Raunser S, Robinson CV, Siegel RM, Walz T, Wu H. The Fas-FADD death domain complex structure reveals the basis of DISC assembly and disease mutations. Nat Struct Mol Biol, 2010, 17: 1324-1329

29 Hou F, Sun L, Zheng H, Skaug B, Jiang QX, Chen ZJ. MAVS forms functional prion-like aggregates to activate and propagate antiviral innate immune response. Cell, 2011, 146: 448-461

30 Qiao Q, Yang C, Zheng C, Fontan L, David L, Yu X, Bracken C, Rosen M, Melnick A, Egelman EH, Wu H. Structural architecture of the CARMA1/Bcl10/MALT1 signalosome: nucleation-induced filamentous assembly. Mol Cell, 2013, 51: 766-779

31 Lu A, Magupalli VG, Ruan J, Yin Q, Atianand MK, Vos MR, Schroder GF, Fitzgerald KA, Wu H, Egelman EH. Unified polymerization mechanism for the assembly of ASC-dependent inflammasomes. Cell, 2014, 156: 1193-1206

32 Wu B, Peisley A, Tetrault D, Li Z, Egelman EH, Magor KE, Walz T, Penczek PA, Hur S. Molecular imprinting as a signal-activation mechanism of the viral RNA sensor RIG-I. Mol Cell, 2014, 55: 511-523

33 Xu H, He X, Zheng H, Huang LJ, Hou F, Yu Z, de la Cruz MJ, Borkowski B, Zhang X, Chen ZJ, Jiang QX. Structural basis for the prion-like MAVS filaments in antiviral innate immunity. eLife, 2014, 3: $\mathrm{e} 01489$

$34 \mathrm{Wu} \mathrm{H}$. Higher-order assemblies in a new paradigm of signal transduction. Cell, 2013, 153: 287-292

35 Li J, McQuade T, Siemer AB, Napetschnig J, Moriwaki K, Hsiao YS, Damko E, Moquin D, Walz T, McDermott A, Chan FK, Wu H. The RIP1/RIP3 necrosome forms a functional amyloid signaling complex required for programmed necrosis. Cell, 2012, 150: 339-350

36 Lenz G, Davis RE, Ngo VN, Lam L, George TC, Wright GW, Dave SS, Zhao H, Xu W, Rosenwald A, Ott G, Muller-Hermelink HK, Gascoyne RD, Connors JM, Rimsza LM, Campo E, Jaffe ES, Delabie
J, Smeland EB, Fisher RI, Chan WC, Staudt LM. Oncogenic CARD11 mutations in human diffuse large B cell lymphoma. Science, 2008, 319: 1676-1679

37 Cai X, Chen J, Xu H, Liu S, Jiang QX, Halfmann R, Chen ZJ. Prion-like polymerization underlies signal transduction in antiviral immune defense and inflammasome activation. Cell, 2014, 156: 1207-1222

38 Granier S, Kobilka B. A new era of GPCR structural and chemical biology. Nat Chem Biol, 2012, 8: 670-673

39 Tay S, Hughey JJ, Lee TK, Lipniacki T, Quake SR, Covert MW. Single-cell NF-kappaB dynamics reveal digital activation and analogue information processing. Nature, 2010, 466: 267-271

40 Kagan JC, Magupalli VG, Wu H. Supramolecular organizing centres: location-specific higher-order signalling complexes that control innate immunity. Nat Rev Immunol, 2014, 14: 821-826

41 Kagan JC, Medzhitov R. Phosphoinositide-mediated adaptor recruitment controls Toll-like receptor signaling. Cell, 2006, 125: 943-955

42 Bonham KS, Orzalli MH, Hayashi K, Wolf AI, Glanemann C, Weninger W, Iwasaki A, Knipe DM, Kagan JC. A promiscuous lipid-binding protein diversifies the subcellular sites of toll-like receptor signal transduction. Cell, 2014, 156: 705-716

43 Seth RB, Sun L, Ea CK, Chen ZJ. Identification and characterization of MAVS, a mitochondrial antiviral signaling protein that activates NF-kappaB and IRF 3. Cell, 2005, 122: 669-682

44 Horner SM, Liu HM, Park HS, Briley J, Gale M Jr. Mitochondrial-associated endoplasmic reticulum membranes (MAM) form innate immune synapses and are targeted by hepatitis $\mathrm{C}$ virus. Proc Natl Acad Sci USA, 2011, 108: 14590-14595

45 Dixit E, Boulant S, Zhang Y, Lee AS, Odendall C, Shum B, Hacohen N, Chen ZJ, Whelan SP, Fransen M, Nibert ML, Superti-Furga G, Kagan JC. Peroxisomes are signaling platforms for antiviral innate immunity. Cell, 2010, 141: 668-681

46 Paul S, Kashyap AK, Jia W, He YW, Schaefer BC. Selective Autophagy of the Adaptor Protein Bcl10 Modulates T Cell Receptor Activation of NF-kappaB. Immunity, 2012,

47 Rossman JS, Stoicheva NG, Langel FD, Patterson GH, LippincottSchwartz J, Schaefer BC. POLKADOTS are foci of functional interactions in T-Cell receptor-mediated signaling to NF-kappaB. Mol Biol Cell, 2006, 17: 2166-2176

48 Sahillioglu AC, Sumbul F, Ozoren N, Haliloglu T. Structural and dynamics aspects of ASC speck assembly. Structure, 2014, 22: $1722-1734$

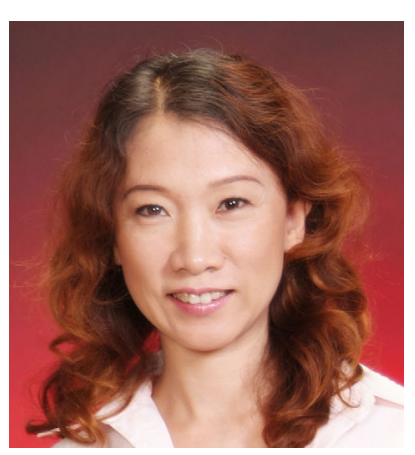

Biographical Sketch

Wu Hao received her pre-medical training at Peking University from 1982 to 1985 and studied Medicine at Peking Union Medical College from 1985 to 1988. She obtained her Ph.D. degree in Biochemistry from Purdue University in 1992 and performed postdoctoral training at Columbia University. She became an Assistant Professor at Weill Cornell Medical College in 1997 and was promoted to Professor in 2003. In 2012, she moved to Harvard Medical School as Asa and Patricia Springer Professor of Biological Chemistry and Molecular Pharmacology, and as Senior Investigator in the Program in Cellular and Molecular Medicine at Boston Children's Hospital. Dr. Wu Hao has received a number of honors, including Howard Hughes Medical Institute pre-doctoral fellowship, Aaron Diamond postdoctoral fellowship, Pew Scholar award, Rita Allen Scholar award, New York Mayor's Award for Excellence in Science and Technology, Margaret Dayhoff Memorial Award from the Biophysical Society, and Purdue University Distinguished Science Alumni Award. She was elected to the National Academy of Sciences in 2015. 


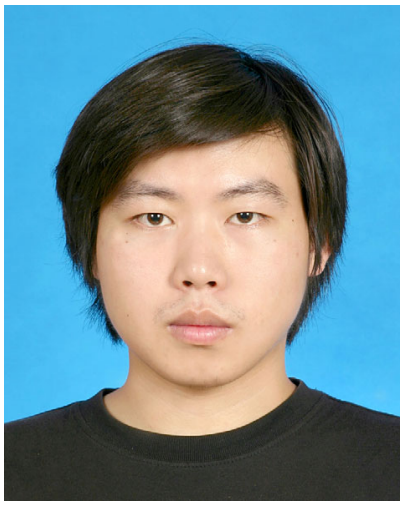

Qiao Qi completed his B.S. degree in the prestigious Yuanpei Program at Peking University and earned his Ph.D. degree with Dr. Xu Rui-Ming at Institute of Biophysics, Chinese Academy of Sciences. In 2012, he joined Dr. Wu Hao's laboratory as a postdoctoral fellow. In his postdoctoral training, he focused on the molecular mechanism of signal transduction in innate and adaptive immune responses. In 2013, Dr. Qiao Qi was awarded the Cancer Research Institute postdoctoral fellowship to support his mechanistic studies on immunity and cancer.

Open Access This article is distributed under the terms of the Creative Commons Attribution License which permits any use, distribution, and reproduction in any medium, provided the original author(s) and source are credited. 